All participants with an interest in the prevention of child maltreatment are invited. The session will be facilitated by Dinesh Sethi, (WHO Regional Office for Europe), Mark Bellis (Public Health Wales), and Dimitrinka Jordanova Pesevska (the former Yugoslav Republic of Macedonia).

\section{Aftermath of disaster}

\section{TUE W 5}

\section{EARTHQUAKE 2015 IN NEPAL, AN EXPERIENCE AT BIR HOSPITAL, KATHMANDU}

Ashok Ratna Bajracharya. Professor and Head, Department of Orthopaedics and Trauma, Bir Hospital, Kathmandu, Nepal

\subsection{6/injuryprev-2016-042156.218}

Background On 25 $5^{\text {th }}$ April 2015 Nepal experienced earthquake of 7.8 Rector scale followed by another one of 6.8 Rector Scale next day with epicentre near Kathmandu. More than 9,000 people died, 25,000 injured, 200 missing, 500000 houses collapsed. Big after-shock 17 days later on $12^{\text {th }}$ May, killed 300, injured 3000 people. Country's central Hospital, Bir Hospital located in Kathmandu is a hub hospital for disaster management; though damaged itself, yet it treated all victims brought here.

Methods All victims brought in immediately and later were triaged, resuscitated, damage control surgery followed later by definite surgery were carried out as per necessity. Records were kept. Challenging logistics and supply were managed in best possible way under the circumstances with aid from abroad later in kinds, man power. As the hospital was damaged too, all in-patients were evacuated to nearby open field. Triage was carried out in open spaces available. Makeshift operation theatres were put up and surgery began as existing ones were damaged too. Side by side institutional rehabilitation was begun too with help from volunteers. Several volunteers from abroad technical and non-technical also helped us a lot.

Results Between 25 April till 17 June 2015, total of 2574 victims attended this hospital. Of them 132 were dead, 1434 were admitted, 1135 underwent Surgery, 568 of Major and 567 of Minor category, 24 died in hospital while on treatment. Of surgery, most (568) were orthopaedic cases, followed by Polytrauma and General Surgery 299, Neurosurgical 39, Chest trauma 24, Burn and Plastics 9, and ENT \& Dental 7. Damage control surgery was performed on 40 victims. Of 190 Orthopaedic surgery, 101 were for Lower Limb, 69 for Upper limb, 20 for Spine and Pelvis. Mechanisms of injury included being buried in rubbles, trapped between heavy objects\& collapsed building, falling objects and panic fleeing.

Conclusions This Natural catastrophe struck least developing country Nepal causing huge loss of life and economy. Rehabilitation and reconstruction is challenging. Since forewarning technology is still unavailable, Hospital preparedness in Emergency program with regular drill is essential for us to perform better in such situation.

\section{ALLEVIATING AFTERMATH OF TERROR THROUGH A PSYCHO-SOCIAL PRO-ACTIVE MODEL FOR FOLLOW-UP}

Freja Ulvestad Kärki. Norwegian Directorate of Health, Oslo
Background In 22 July 2011 a lone wolf terrorist managed to massacre 77 people, mainly youngsters participating in a political youth camp at Utøya Island outside Oslo. To meet the situation characterised as a national trauma a major psycho-social intervention was developed and implemented under the stewardship of health authorities and through consultations with experts, other central stake holders and the exposed themselves.

Methods The intervention was a large-scale pilot targeting the exposed (survivors with families, bereaved with parents and siblings) through a municipality-based individual and collective psycho-social follow-up model. The watchful waiting principle was replaced by pro-activity in the services. The individual needs in the victims were to be monitored by a health professional three times during the first year after terror. Individual contact persons providing a long time follow-up were pointed out in the municipal crisis units. National week-end and county-wise one-day reunions were arranged for the bereaved and the survivors with families. A large capacity building exercise was initiated in order to increase the competency of psychological trauma reactions and conditions in all relevant services.

Results Even if the effect of the interventions on the trauma related conditions is hard to measure there is convincing evidence for the benefit of the pro-active model as well as the benefit of the collective interventions, communicated by the service users themselves. The pro-active principle was embraced by all the exposed as were the national week-end gatherings for the bereaved. 99\% of the latter evaluated the collective intervention as a good or very good help in their grieving process.

Conclusions Even if it is very difficult to evaluate the effect of the intervention model in terms of reduced symptom load in the exposed, pro-activity should be considered as one of the guiding principles in assessing the psycho-social needs of the exposed in major incidents in the future.

\section{The European Injury Data Base (IDB)}

\section{TUE W 6}

\section{THE EUROPEAN INJURY DATA BASE: SUPPORTING INJURY RESEARCH AND POLICY ACROSS EUROPE}

${ }^{1}$ Samantha Turner, ${ }^{1,2}$ Ronan A Lyons, ${ }^{3}$ Wim Rogmans, ${ }^{4}$ Rupert Kisser, ${ }^{5}$ Bjarne Larsen, ${ }^{6}$ Huib Valkenberg, ${ }^{7}$ Dritan Bejko, ${ }^{8}$ Robert Bauer, ${ }^{8}$ Monica Steiner, ${ }^{9}$ Gabriele Ellsaesser. ${ }^{1}$ Far Institute Swansea University, Medical School, UK; ${ }^{2}$ Public Health Wales NHS Trust, UK ${ }^{3}$ Eurosafe, The Netherlands; ${ }^{4}$ Eurosafe, Austria; ${ }^{5}$ National Institute of Public Health, Denmark; ${ }^{6}$ Consumer Safety Institute, The Netherlands; ${ }^{7}$ Luxembourg Institute of Health, Luxembourg; ${ }^{8}$ Austrian Road Safety Board, Austria; ${ }^{9}$ State Office of Environment, Health and Consumer Protection, Germany

\subsection{6/injuryprev-2016-042156.220}

Background Although various injury data sources exist in Europe; many lack sufficient size, scope, detail or comparability, to support injury prevention research or policy development. Emergency department (ED) records offer one of the most comprehensive sources of injury data; however, heterogeneous hospital data collection systems prevent comparative analyses between countries.

Methods As part of the Joint Action on Monitoring Injuries in Europe (JAMIE) project, and now the BRIDGE-Health (BRidging Information and Data Generation for Evidence-based Health Policy and Research) development; the European Commission (EC) funded the development of a standardised European Injury Data 
Base (IDB). The IDB comprises two datasets: the Full Data Set (FDS) and Minimum Data Set (MDS). Although the MDS collects less detail than the FDS; it is simpler for countries to adopt, and still sufficient to allow enumeration of injuries in key areas such as the home, leisure, work, road, falls, sports, and self-harm. Training, guides and rigorous quality checks, ensure consistency across participating countries.

Results To date, 26 countries have submitted 7,170,069 ED records (years 2009-2014) to the IDB in MDS format, and 20 countries have provided reference population data, enabling the calculation of incidence rates. As an exemplar, in 2013, incidence rates for all injuries varied between $11.43 \%$ in Luxembourg to $3.98 \%$ in Finland; the reasons behind these variations will be discussed at the conference. The MDS has provided a valuable source of data for several organisations across Europe, and can be accessed via several channels, including an online tool. The MDS strives to contribute data to the "European Core Health Indicators" (ECHI), "home, leisure and school accidents" (ECHI29) indicator.

Conclusions The MDS provides Europe with a valuable source of comparable injury data. Work is currently underway to ensure the MDS data is as valid and representative as possible.

\section{A EUROPEAN CORE HEALTH INDICTOR FOR HOME AND LEISURE INJURIES (ECHI-29)}

${ }^{1}$ Rupert Kisser, ${ }^{2}$ Samantha Turner, ${ }^{2,3}$ Ronan A Lyons, ${ }^{4}$ Wim Rogmans, ${ }^{5}$ Bjarne Larsen, ${ }^{6}$ Huib Valkenberg, ${ }^{7}$ Dritan Bejko, ${ }^{8}$ Robert Bauer, ${ }^{8}$ Monica Steiner. ${ }^{1}$ Eurosafe, Austria; ${ }^{2}$ Farr Institute Swansea University, Medical School, UK; ${ }^{3}$ Public Health Wales NHS Trust, UK; ${ }^{4}$ Eurosafe, The Netherlands; ${ }^{5}$ National Institute of Public Health, Denmark; ${ }^{6}$ Consumer Safety Institute, The Netherlands; ${ }^{7}$ Centre d'Etudes en Santé Publique, Luxembourg; ${ }^{8}$ Austrian Road Safety Board, Austria

\subsection{6/injuryprev-2016-042156.221}

Background Within the framework of the EU health information system, a European Core Health Indictor (ECHI) is foreseen on home and leisure, sport and school injuries (ECHI-29). However in 2010, there were no reasonably comparable injury data available for these areas, but emergency department (ED) records offered a most valuable source of information.

Methods Based on previous experiences, the Joint Action on Monitoring Injuries in Europe (JAMIE) project (2010-2013) has developed a comprehensive Minimum Data Set (MDS), which can be recorded in EDs without adding noteworthy burden to staff and patients. MDS contains diagnoses and allows the enumeration of injuries in key areas as road, workplace, home and leisure, sport, school, work place, self-harm and assault. MDS data can be recorded directly or extracted from other datasets as ICD-10 or IDB-FDS (Full Data Set), which is used for recording injuries related to consumer products.

Results During 2011-2013, 26 countries have submitted national MDS data sets to the European Injury Data Base (IDB) in MDS format, and 20 countries have provided reference population data, enabling the calculation of ECHI29. There are about 31 million home, leisure, sport and school injuries each year in the EU-28, which is $76 \%$ of all injuries treated in EDs. 700.000 injuries occur at school, 5.9 million during sporting, and 24.7 million at home or during other leisure time activities. The average incidence rate was $6.1 \%$, with a variation between $4.9 \%$ in Portugal and $8.9 \%$ in Luxembourg.

Conclusions MDS records from emergency departments can be the source for meaningful injury statistics and allow a differentiation by settings, age-groups and type of injuries. However, considerable variations between countries indicate that improvement of national methods is needed in order to increase crosscountry comparability.

\section{COMBINING SURVEY AND REGISTER BASED DATA TO ESTIMATE BURDEN OF INJURIES AMONG ADOLESCENTS}

${ }^{1}$ Dritan Bejko, ${ }^{2}$ Rupert Kisser, ${ }^{3,4}$ Ronan A Lyons, ${ }^{5}$ Yossi Harel-Fisch, ${ }^{6}$ Bjarne Larsen, ${ }^{7}$ Wim Rogmans, ${ }^{2}$ Samantha Turner, ${ }^{8}$ Robert Bauer, ${ }^{9}$ Gabrielle Ellsessaer, ${ }^{10}$ Huib Valkenberg. ${ }^{1}$ Luxembourg Institute of Health, Luxembourg; ${ }^{2}$ Eurosafe, Austria; ${ }^{3}$ Farr Institute Swansea University, Medical School, UK; ${ }^{4}$ Public Health Wales NHS Trust, UK; ${ }^{5}$ Bar Ilan University, Israe; ${ }^{6}$ National Institute of Public Health, Denmark; ${ }^{7}$ Eurosafe, The Netherlands; ${ }^{8}$ Austrian Road Safety Board, Austria; ${ }^{9}$ Landesamt Brandenburg Für Umwelt, Gesundheit Und Verbraucherschutz, Germany; ${ }^{10}$ Consumer Safety Institute, The Netherlands

\subsection{6/injuryprev-2016-042156.222}

Background Children and adolescents have the highest risk of injury. Emergency department (ED) data provide the best opportunity for estimating the burden of hospital treated injuries. Survey based data remains the only source of information for out of hospital medically treated injuries in many countries. The purpose of this study was to describe the incidence of selected injuries among adolescents in 16 European countries using surveybased and registry based methods.

Methods Survey based data were collected during the 2013/2014 wave of the Health Behaviour in School Aged Children (HBSC) study in 42 countries. Children reported the number of medically treated injuries for the last 12 months, the severity of the most serious injury as well as the place of occurrence and the activity when injured. The Registry based data supplied to the European Injury Data Base (IDB) for the period 2013-2014 provided detailed information about causes and circumstances of ED treated injuries for the same period and age group.

Results Detailed analyses were possible using IDB data from 16 countries and HBSC data from 42 countries. Both sources confirm an inter-country variability for burden of injuries among adolescents. Due to different methodologies in defining an injury case, comparison is not always possible between registry based and survey based data collection.

Conclusions Survey based and register based data can be used as complementary sources of information to have a full picture of injury burden among adolescents in many European countries.

\section{ARE REGISTER-BASED DATA BETTER THAN SURVEYS IN ESTIMATING BURDEN OF INJURIES AMONG ADULTS? RESULTS FROM LUXEMBOURG}

${ }^{1}$ Dritan Bejko, ${ }^{1}$ Maria Ruiz-Castell, ${ }^{2,3}$ Ronan A Lyons, ${ }^{4}$ Rupert Kisser, ${ }^{5}$ Bjarne Larsen, ${ }^{6}$ Wim Rogmans, ${ }^{2}$ Samantha Turner, ${ }^{7}$ Robert Bauer, ${ }^{8}$ Gabrielle Ellsessaer, ${ }^{9}$ Huib Valkenberg. 'Luxembourg Institute of Health, Luxembourg; ${ }^{2}$ Farr Institute Swansea University, Medical School, UK; ${ }^{3}$ Public Health Wales NHS Trust, UK; ${ }^{4}$ Eurosafe, Austria; ${ }^{5}$ National Institute of Public Health, Denmark; ${ }^{6}$ Eurosafe, The Netherlands; ${ }^{7}$ Austrian Road Safety Board, Austria; ${ }^{8}$ Landesamt Brandenburg Für Umwelt, Gesundheit Und Verbraucherschutz, Germany; ${ }^{9}$ Consumer Safety Institute, The Netherlands

\subsection{6/injuryprev-2016-042156.223}

Background Injury is a major cause of mortality and morbidity. The emergency department (ED) registry based data, provides a cost-effective way to estimate the burden of injuries. Previous studies in general population have suggested that survey based data collection is not efficient and suffers from recall or selection bias. The aim of this study was to compare the yearly incidence 